Voix et Images

\title{
Un goût d'amertume, un parfum de désenchantement... et leur antidote
}

\section{Robert Major}

Volume 14, numéro 1 (39), automne 1988

France Théoret : narratrice de la subjectivité

URI : https://id.erudit.org/iderudit/200756ar

DOI : https://doi.org/10.7202/200756ar

Aller au sommaire du numéro

Éditeur(s)

Université du Québec à Montréal

ISSN

0318-9201 (imprimé)

1705-933X (numérique)

Découvrir la revue

Citer cet article

Major, R. (1988). Un goût d'amertume, un parfum de désenchantement... et leur antidote. Voix et Images, 14(1), 120-123. https://doi.org/10.7202/200756ar d'utilisation que vous pouvez consulter en ligne.

https://apropos.erudit.org/fr/usagers/politique-dutilisation/ 
Essai

\title{
Un goût d'amertume, un parfum de désenchantement... et leur antidote
}

\author{
par Robert Major, Université d'Ottawa
}

Chacun, aujourd'hui, a ses raisons de désespérer. L'époque, en effet, n'y regarde pas de près et en offre pour tous les goûts. L'intellectuel québécois, autant que tout autre, peut être abattu par la prolifération nucléaire, la pollution protéiforme, la menace bactériologique ou la vulgarité galopante; mais il n'a, à vrai dire, qu'une seule source d'angoisse, qu'une tunique de Nessus à laquelle reviennent immanquablement toutes ses pensées: la survivance de la race.

Allan Bloom peut bien, dans son livre percutant ${ }^{1}$, s'inquiéter du déclin de la culture générale, s'interroger sur l'ignorance barbare de ses étudiants, mettre en cause la démission morale des écoles et des universités de son pays, regretter l'époque de la formation humaniste et des authentiques valeurs: ses cris d'alerte ne visent que les éducateurs de son pays; les U.S.A. ne sont pas menacés dans leur survie et dans leur (in)culture. Les observateurs plus sereins de ce pays savent que depuis fort longtemps déjà, les «eggheads» y sont tenus en piètre estime officielle et populaire. Mais l'intellectuel québécois, lorsqu'il s'inquiète de la culture québécoise, pose du coup la question de l'existence même de la collectivité: elle n'est que culture. Toute mutation suppose sa disparition. Et cette angoisse devant l'avenir est amplement nourrie par des situations multiples et par des événements plus ou moins récents. C'est ainsi que, à retardement, l'échec référendaire produit ses effets et que la question existentielle, toujours la même, reprend toute son acuité dans des publications récentes.

Terré dans sa Renardière (le nom de sa maison d'été), Marcel Rioux (Rioux dit Renard) lèche ses blessures multiples et nous livre ses réflexions fort pessimistes sur l'avenir du Québec: Une saison à la Renardière ${ }^{2}$. Tout bien considéré, il ne voit guère de raisons d'espérer. Déçu du marxisme, désenchanté par les socialismes concrets qui s'en réclament, trahi par le P.Q., inquiété par la poltronnerie populaire, se méfiant des politiciens-épiciers, alarmé par l'américanisation rapide de ses compatriotes, conscient que toutes les causes qu'il a défendues - indépendance du Québec, socialisme, autogestion, anticléricalisme - sont en déroute, il a bien raison d'être maussade. Pendant cette triste saison, le soleil ne perce que rarement: que lorsqu'il est question des femmes, par exemple, ou bien des différences entre Québécois et Canadien anglais. Un mince rayon d'espoir est même perceptible: d'autres chemins de liberté (p. 44) seraient à penser. Mais lesquels justement? On ne le saura jamais. Non, l'essentiel de ce livre est bien ailleurs: dans un ton de désespérance et dans la conviction profonde 
que le Québec [...] depuis 1980 [...] semble irrémédiablement aller à vau-l' eau (post-scriptum). Rarement couverture (avec sa photo ensoleillée de jolie maison jaune, face au large) aura-t-elle été aussi trompeuse sur le contenu d'un livre.

Quelques mois avant la publication de cet essai désabusé, le même éditeur (l'Hexagone) lançait l'œuvre touffue, exubérante, de Heinz Weinmann: Du Canada au Québec. Généalogie d'une histoire ${ }^{3}$. Le lecteur se prend à regretter que Marcel Rioux n'ait pas pu en prendre connaissance avant de se replier dans son terrier (ou avant de publier le fruit amer de cette retraite). Cela lui aurait peut-être évité de resservir les sempiternels lieux communs (disculpants et finalement rassurants) sur la Défaite de $\mathbf{1 7 6 0}$ ou la décapitation de la bourgeoisie de la Nouvelle-France. Il y aurait peut-être aussi trouvé réponse à quelques-unes des questions étonnamment naïves qu'il formule dans sa chronique. Un sociologue, même s'il choisit de parler comme simple intellectuel engagé (p. 15), peut-il (pouvait-il) vraiment croire que la chanson québécoise nous ferait déboucher sur l'indépendance (p. 39); ou qu'invoquer la faiblesse de notre nationalisme (p. 47) soit une réponse satisfaisante pour qui cherche à comprendre la défaite référendaire? Faiblesse, on veut bien, mais ce vocabulaire de la culpabilisation (car le vocabulaire religieux, et en particulier celui de la faute, est remarquablement présent dans ce livre d'agnostique ${ }^{4}$ ) nous en apprend peu sur les sources profondes de ces lacunes.

Or, depuis Heinz Weinmann, il n'est plus possible de parler de décapitation au Québec sans peser ses mots. Et difficile de prophétiser la mort d'un Québec moribond, puisqu'il vient à peine de naître! Le 17 octobre 1970, entre $15 \mathrm{~h}$ et 21 h, précisément! Ce Québec, évidemment, n'est pas celui que Marcel Rioux souhaiterait, puisqu'il contient, dans le repli le plus secret de son identité, ce que Marcel Rioux et tout nationaliste respectable cherche désespérément à niér: le Canada (dernier avatar du Kanada-Canada). Pour Heinz Weinmann, en effet, la question n'est pas de sortir le Québec du Canada: elle est essentiellement d'extirper le Canada (Kanada-Canada) du Québec. Opération délicate car il s'agit - pour employer une image que Heinz Weinnman ne désavouerait certes pas d'une véritable éviscération.

Mais avant d'en arriver là, à quel prodigieux voyage ne nous convie-t-il pas! Voyage dans le temps, voyage dans l'espace, voyage vers les centres multiples de notre identité. Car on n'est pas philosophe allemand impunément. Et si, de plus, on passe par Paris avant de remonter le Saint-Laurent, l'esprit de système est doublement assuré (double bind!). L'ensemble de la culture occidentale, les grands prêtres de la pensée moderne (Freud en tête), et des rangs serrés d'historiens de tout horizon sont mis à contribution dans une ambitieuse entreprise totalisante: embrasser l'alpha et l'oméga, fixer le terminus a quo et le terminus ad quem, et, dans une vaste vision d'ensemble, expliquer le Québec aux Québécois.

Le pari est-il tenu? Remarquablement. Cet essai éblouissant est un des livres les plus intelligents, les plus provocateurs et les plus amusants des 
dernières années: d'une largeur de vues, d'une perspicacité et d'une finesse analytique dont on voit peu d'exemples ici. Si ambitieux que les spécialistes de tout acabit trouveront facilement à redire ${ }^{5}$; si polémique qu'il ne saurait échapper impunément à tous ceux qu'il questionne; si systématique qu'il gomme plutôt allègrement les détails gênants; mais si stimulant qu'il se lit avec un énorme plaisir et si efficace comme révélateur qu'on ne saurait désormais s'en passer.

La thèse de Heinz Weinmann, abondamment illustrée par une véritable fringale analytique, est, au fond, malgré ses multiples ramifications, fort simple: depuis toujours, depuis les premiers gestes fondateurs (et même avant), Québec et Canada sont inextricablement liés dans l'inconscient des Québécois. Bien malin qui saurait défaire ce nœud gordien. Quant à le trancher... à quel prix ? Estil certain que ce geste radical ouvre la voie à l'empire de l'Asie (de la Laurentie)? Jadis, le chanoine Groulx, lui, suggérait (l'Appel de la race) d'utiliser, plutôt qu'une épée, un coin de fer pour faire sauter les couches qui recouvraient et étouffaient la pureté raciale des Canadiens français. Le chanoine Groulx: on y revient toujours. Il est une présence constante dans l'essai de Heinz Weinmann, une référence obligatoire dans celui de Marcel Rioux, et l'objet d'une réflexion soutenue dans le livre que Fernand Dumont publiait au même moment chez le même éditeur.

Le Sort de la culture ${ }^{6}$ est un recueil d'essais courts qui, comme les précédents livres abordés dans cette chronique, pose la question de la culture québécoise. La culture comme problème. Mais le penchant philosophique s'accentuant de livre en livre chez Fernand Dumont, tout est vu de haut et de loin. Bien que la plupart de ces essais aient été écrits après 1980, non seulement la crise de 1980 ne constitue pas le terreau fécond des réflexions de l'auteur, comme c'est le cas chez Marcel Rioux et Heinz Weinmann, mais il n'en est aucunement question. Philosophie de l'histoire, réflexion morale, qui se dégage avec facilité de la gangue des contingences et se complaît, il me semble, avec trop d'évidence, dans un style questionneur et onctueux. D'un lieu (moral) suffisamment éloigné, le sort de la culture n'est guère inquiétant. Il est possible même de juger que l'état de crise est consubstantiel à toute authentique culture qui ne vit que sous la menace de sa dissolution.

On veut bien. Mais une telle impassibilité, une telle hauteur de ton et de vue, un tel niveau d'abstraction laisse aussi le lecteur quelque peu froid et distant. Déjà en 1968 (le Lieu de l'homme), Fernand Dumont définissait la culture par la distance qu'elle maintenait avec la vie quotidienne: la réflexion sur la culture, plutôt que de chercher à réduire cette distance, l'a au contraire épousée et volontairement accentuée, comme si elle allait de soi. Fort bien, et livre admirable sans doute; mais on me permetra de préférer la chaleur et la passion et l'angoisse mal contenue de la Vigile du Québec.

1 Allan Bloom, l'Âme désarmée. Essal sur le déclin de la culture générale, Montréal, Guérin, 1987, 332 p.

2 Marcel Rioux, Une salson à la Renardière, Montréal, l'Hexagone, 1988, 90 p. 
3 Heinz Weinmann, Du Canada au Québec. Généalogie d'une histolre, Montréal, l'Hexagone, 1987, 487 p.

4 Ce que Fernand Dumont signale sur la religion du nationalisme québécois (voir note 6 , ci-dessous, p. 259) semble ici pertinent :

Un temps, on a cru qu'un néo-nationalisme élaborerait le discours de la nouvelle société québécoise, la ferveur politique remplaçant la ferveur religieuse. On sait ce qu'il en est advenu au cours des annés dernieres. Certes, le nationalisme n'est pas disparu. Mais il n'a plus, dans les débats publics tout au moins, la résonance qu'on a connue. Il est rentré dans la vie privé. Une génération en est meurtrie. Il faut entendre, d ce sujet, les aveux de beaucoup d'hommes et de femmes dans la quarantaine (dans la soixantaine!) pour qui la politique avait servi de religion et qui se retrouvent, comme me le disait l'un d'entre eux, corphelins et sans espérance.. C'est un drame religieux, celui-la aussi.

5 Je signale par exemple à l'anteur que c'est Arché, un Écossais, et non André qui perd ses jambes (p. 282) : son rapprochement avec José est donc fautif et son analyse, partant, unijambiste.

6 Fernand Dumont, le Sort de la culture, Montréal, l'Hexagone, 1987, 333 p. 